\title{
La violencia contra las mujeres a través de la tecnología
}

\author{
Soledad Venegas Nava ${ }^{1}$
}

Palabras clave: Entornos digitales, violencia, género, ciberacoso, redes de apoyo.

\begin{abstract}
El siguiente artículo expone una realidad sobre la situación de la violencia que sufren las mujeres a través de la tecnología. Diversas han sido las causas que han llevado a la reproducción de las conductas negativas basadas en una ideología patriarcal, machista y misógina que, a través del ejercicio de poder y dominación (Bourdieu, 1998), se humilla, expone y victimiza las mujeres, por el simple hecho de serlo en los entornos digitales. Los espacios digitales en Internet, redes sociales, plataformas y entornos de interacción digital, son sitios en los cuales, las mujeres también tienen derecho de participar libremente haciendo uso y apropiándose de las tecnologías, ya que vivimos una nueva forma de relacionarnos y de vivir en la llamada tecnocultura (Bonder, 2002), en donde las mujeres crean y participan en la ciudadanía digital, para transformar sus realidades una vez que tienen acceso a la sociedad del conocimiento, a la participación de redes, de la comunicación y la economía digital, ya que contribuye en la autonomía y empoderamiento de las mismas.
\end{abstract}

\section{Introducción}

En la actualidad, la sociedad a nivel global atraviesa por una tercera revolución que altera la dinámica de la vida tal como la conocíamos. A esta se le llama la revolución tecnológica y digital, basada en servicios e información, la

1 Soledad Venegas Nava es Licenciada en Informática, especialista en la práctica docente, Diplomada en Estudios de las Mujeres Feminismo y descolonización, Maestra en Desarrollo Regional y Tecnológico, estudiante de Doctorado en Ciencias del Desarrollo Regional y Tecnológico en el Instituto Tecnológico de Oaxaca, México, con temas sobre el empoderamiento de las mujeres en ciencias y tecnología, trabaja con temas de violencias en los espacios digitales, y seguridad digital. soledad@venegasnava.com 
velocidad por la nanotecnología, la Bigdata en la sociedad del conocimiento basada en emociones sensoriales, en dinámicas colaborativas con identidades virtuales que cobran vida en la tecnocultura como lo menciona Bonder (2002), con sus nuevas formas, reglas y protocolos de comunicación como parte de los derechos digitales en el ciberespacio.

\section{Los prosumidores en internet}

Hoy, la realidad nos obliga a estar a la vanguardia en la tecnología y participar activamente como prosumidores en los entornos digitales tanto hombres como mujeres por igual en todos los sectores de la sociedad. Las redes sociales son hoy una necesidad de comunicación y de conocimiento segundo a segundo. Así, un estudio realizado por Cumus Media, según Trece Bits (2017), establece que en un minuto en internet ingresan 900,000 usuarios a Facebook; en Instagram se publican 46,200 fotos; se envían 452,000 Tweets; se descargan 342,000 aplicaciones; se realizan 3.5 millones de búsquedas en Google; se reproducen 40,000 canciones, 4.1 millones de vídeos en YouTube, entre otras tantas actividades tales como que se llevan a cabo compras en línea por valor de \$751,522 dólares. Realmente, es una revolución efervescente para una sociedad que no concibe su mundo sin la internet y las tecnologías cada vez más nano e integradas en la vida diaria, como son las relaciones de pareja. Tal es el caso de Tinder con 990,000 encuentros sexuales. Una gran dinámica social ha llegado y está para quedarse y seguir creciendo, pero tiene sus desafios sobre todo en la seguridad digital.

2 La palabra prosumidor, o también conocida como prosumer, es un acrónimo formado por la fusión original de las palabras en inglés producer (productor) y consumer (consumidor). Se trata de un término utilizado en ámbitos muy diferentes, desde la agricultura a la informática, la industria o el mundo de la afición. www.wikipedia.org 
Figura 1. Un minuto en internet.

"2017 Esto pasa en un minuto en Internet".

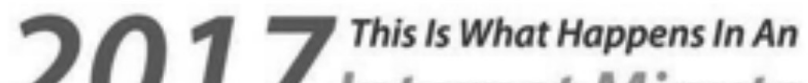 \\ 2017 Internet Minute}

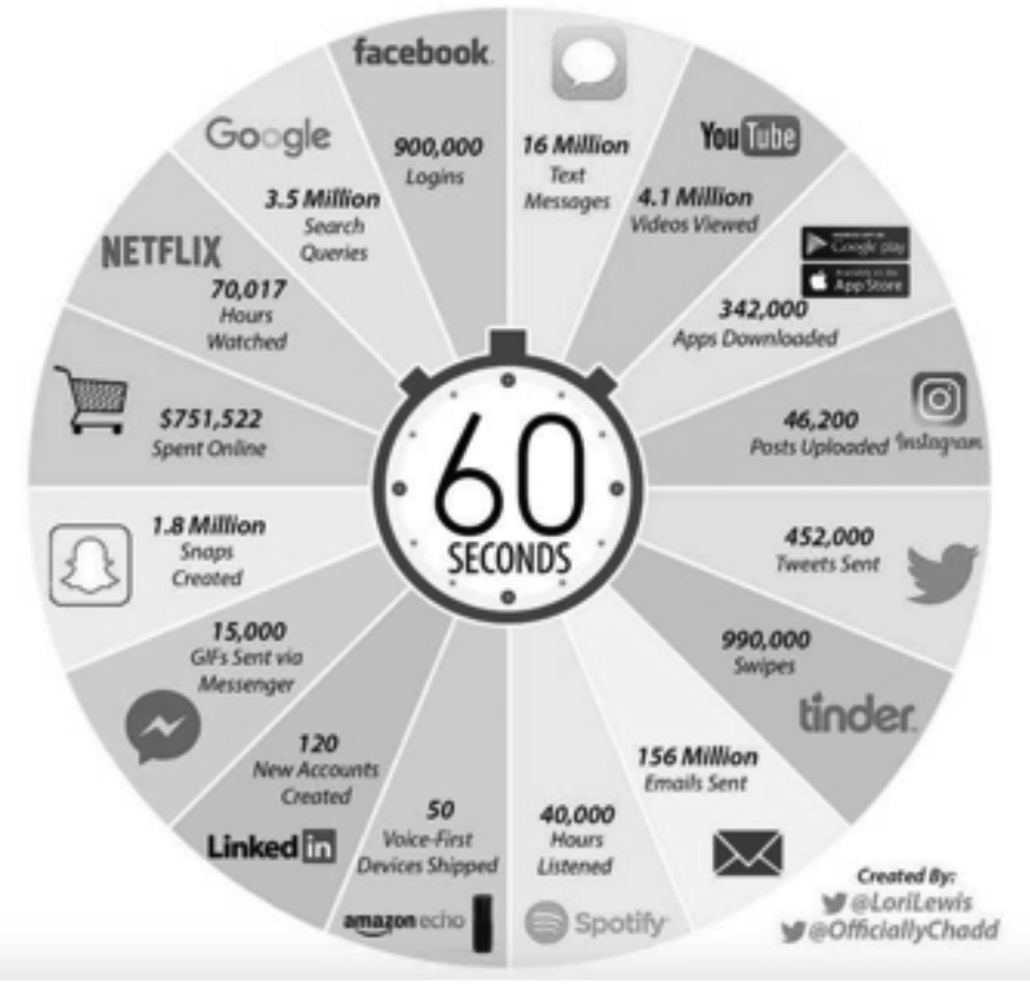

Fuente: Trece Bits. Redes sociales y tecnología, 2017

\section{Situación actual de la violencia contra las mujeres a través de las tecnologías}

La sociedad del intercambio y el trabajo colaborativo, así como la información instantánea en tiempo real, a través de las redes sociales o canales en vivo por medio de internet y los dispositivos inteligentes, se vuelve una necesidad y el principal medio para que la sociedad del conocimiento sea posible. La revolución digital y tecnológica ha contribuido a potenciar las capacidades y libertades de las personas, sin embargo, no solo las características positivas se han favorecido, también las conductas negativas se han visto reflejadas en el ciberespacio, basándose en el anonimato en internet (Martínez y Mújica, 2010). Donde "lo primero que surge es la cosificación del cuerpo femenino en infinidad de sitios web, en todos los formatos que permite la flexibilidad 
de internet, y como claros ejemplos de estereotipos y discriminación hacia las mujeres", sobre todo hombres, cuyas prácticas misóginas, machistas y de dominación, se han hecho presentes provocando con ello acciones negativas que han afectado de manera grave a la sociedad, principalmente a las niñas, niños y mujeres, tales como la trata, el ciberacoso, ciberbullying, grooming, sexting, pornografía, pornovenganza, suplantación de identidad y ciberdelincuencia, por citar algunos tipos de violencia digital.

Los efectos resultan lamentables cuando las cifras de denuncias son tan altas y siguen creciendo. Según la Encuesta Nacional sobre la Disponibilidad y Uso de las TIC en Hogares (ENDUTIH, 2016), 47.9\% de las mujeres de 12 y más años han sido víctimas de ciberacoso; por grupos de edad de 12 a 19 años, 28\%; de 20-29 años, 30\%; de 30-49 años, 20.8\%; y de 50 y más: 9\%. Salen afectadas las mujeres de todo tipo de educación donde, sin escolaridad son el 10\%; con tipo básico, 17.5\%; con tipo medio superior, 26\%; y con nivel universitario, 35.7\%; la media nacional es de 24.5\%. Oaxaca ocupa el 23vo lugar de ciberacoso con $23 \%$ en relación con la media nacional.

Figura 2. Porcentaje de mujeres de 12 años y más que vivió ciberacoso, según tipo de acoso experimentado en 2015.

Recibir spam o virus

Recibir contenido multimedia inapropiado

Recibir llamadas negativas

Ser contactadas por identidades falsas

Registradas en sitios web

Recibir mensajes negativos o misóginos

Robo de identidad

Rastrear sus sitios web

Dañar publicando tu información

Obligada a dar contraseña

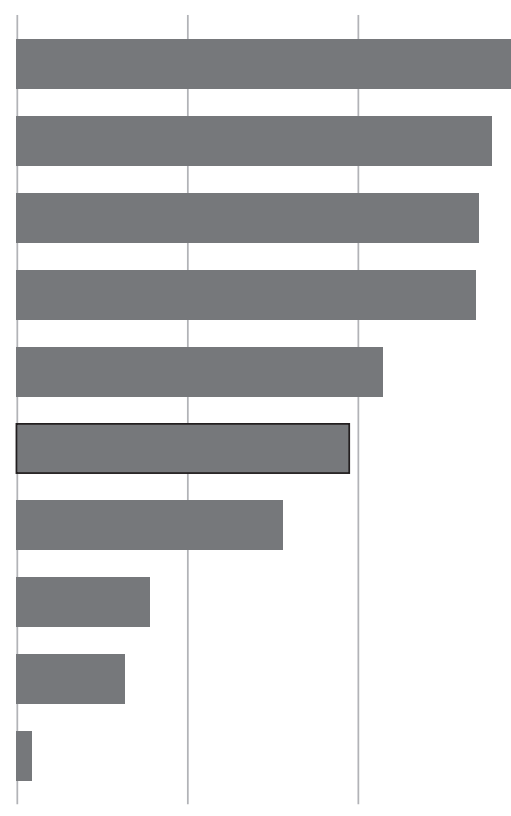

$0 \%$ 
En la Figura 2 se muestran los datos porcentuales según el tipo de ciberacoso que han sufrido las mujeres de 12 años y más. La principal causa es la de recibir spam o virus (23.7\%), le sigue recibir contenido inapropiado (13.8\%) y recibir llamadas negativas (13.5\%). En esta encuesta sólo se registró 0.4 \% de las mujeres que las obligan a proporcionar su contraseña a la persona violenta.

Asimismo, el estudio realizado por Barrera y Lourdes (2017) sobre la violencia en línea contra las mujeres en México menciona que 66\% de las mujeres mayores de 15 años ha vivido alguna forma de violencia de género. En cuanto al tipo de violencia relacionada con la tecnología se refieren a aquellos cometidos, instigados o agravados, de manera parcial o total, por el uso de las Tecnologías de la Información y la Comunicación (TIC), plataformas de redes sociales y correo electrónico, y que causan daño psicológico y emocional, refuerzan los prejuicios, dañan la reputación, causan pérdidas económicas y plantean barreras a la participación en la vida pública y pueden conducir a formas de violencia sexual y otras formas de violencia física.

La Asociación para el Progreso de las Comunicaciones (APC, 2015) a través del mapeo de violencia contra las mujeres relacionado con la tecnología reveló que se registraron 1,126 hechos perpetrados del 2012 al 2014 en siete países (incluido México). En ese mismo reporte se plantea que son las mujeres jóvenes de entre 18 y 30 años, las más vulnerables en los espacios digitales, que $11 \%$ de los casos denuncia daños físicos, lo cual significa que internet se utiliza para facilitar la violencia en la vida real. Asimismo, en el reporte se informa que el 40 \% de estos actos violentos contra las mujeres fueron cometidos por personas conocidas de las victimas, como parejas, exparejas, etc. Las mujeres que experimentan violencia de género en internet se clasifican en tres categorías principales: en relación íntima, profesional con perfil público, o sobreviviente de violencia.

La principal red social, Facebook (26\%) y los teléfonos celulares (19\%) son las plataformas más denunciadas por los actos de violencia ejecutados contra ellas.

A través de este estudio se encontró que $49 \%$ de los casos se denunciaron ante las autoridades y menos de la mitad de ellos (41\%) se investigaron. En la mayoría de estos (33\%) se reporta un daño emocional severo, que impide la plena participación de las mujeres en los espacios digitales y en la vida real, excluyéndolas de su derecho a la libertad del acceso a la participación en el ciberespacio (APC, 2015). 
Figura 3. Mapeo de casos por violencia a través del uso de la tecnología a nivel mundial.

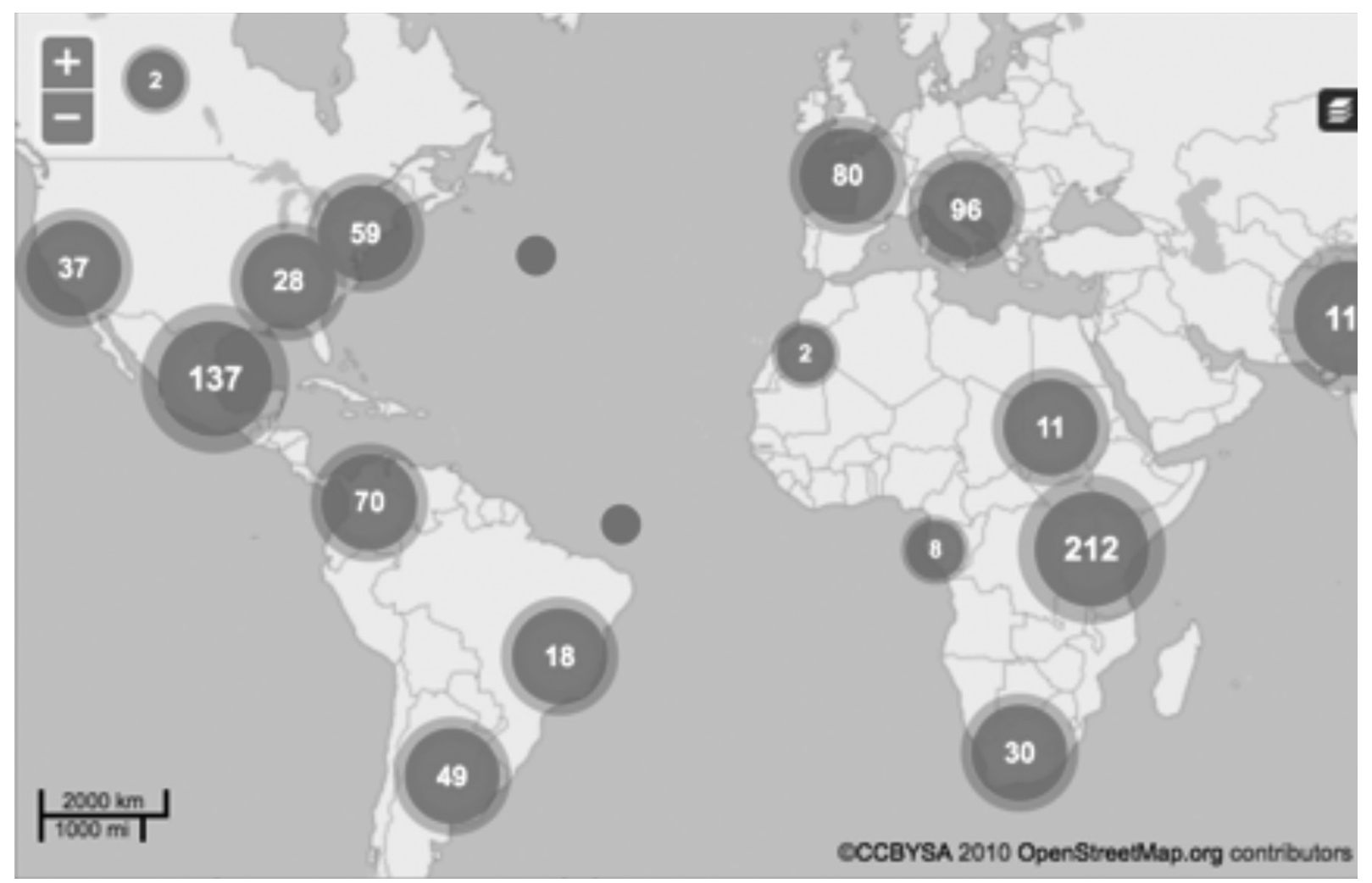

Fuente: Pággina web de Take Back The Tech.

Como se puede apreciar en la Figura 3, cada círculo representa el número de reportes sobre violencia relacionada con la tecnología en cada país. México tiene 137 casos reportados.

\section{Cómo actuar para detener la violencia}

Como sociedad no podemos seguir permitiendo que las mujeres dejen de participar en los entornos digitales por la violencia, es su derecho de acceso al conocimiento, a la creación de redes de apoyo y de intercambio de conocimientos, a la economía digital, acceso a la participación pública, de libre organización y libertad de expresión, así como a la libertad de sus derechos sexuales y reproductivos en internet. Conocer sus derechos hace posible el avance hacia la construcción de una sociedad más justa y equitativa, aspirando a la igualdad. Es cuestión de cambiar el paradigma principalmente en las mujeres, al saber que es su derecho y ampliar sus capacidades es un deber. 
Por ello, es necesario no quedarse callada, hacer la denuncia, crear redes de amigas y personas seguras, que apoyen a visibilizar a la violencia y saber que no estás sola; documenta las agresiones; haz capturas de pantallas, graba con audio o vídeo, toma fotos pues son tus evidencias para la denuncia ante las autoridades; acércate a los espacios de mujeres apoyando a más mujeres. En cada institución existe un departamento de igualdad de género, así como en las organizaciones de la sociedad civil que te apoyan y orientan sobre estos tipos de violencia. Te invitamos a que visites las páginas web siguientes: Página web de Take Back The Tech, Página web de Colnodo. Uso estratégico de Internet para el desarrollo. Derechos de las mujeres en los espacios digitales, así como en la Fanpage de la Dirección de Equidad de Género de la UABJO, que te ayudarán a tener más información y encontrar una red que te ayuda, orienta y protege, recuerda que en tus manos está hacer la diferencia. En este sentido, es necesario impulsar el empoderamiento de las mujeres en ciencia y tecnología. Es nuestro derecho participar activamente en un mundo donde la tercera revolución tecnológica nos obliga a estar en el espacio virtual bajo igualdad de condiciones y sin violencia por el simple hecho de ser mujeres.

Se requiere capacitar a funcionarios y administrativos para prevenir y sancionar la violencia en internet contra las mujeres, niñas y niños. Al mismo tiempo, es importante promover espacios digitales de información y protocolos de seguridad digital, desarrollar mensajes positivos replicables usando las TIC, generando una cultura del respeto y relaciones positivas y de combate a la violencia, realizando pronunciamientos conjuntos, foros de discusión entre mujeres y personas sensibles al problema de la violencia contra las mujeres, las niñas y los niños principalmente.

En palabras de APc es necesario "Transitar el ciberespacio es nuestro derecho y disfrutar de una vida libre de violencia en todos los espacios que ocupemos. Actúa, ponle fin a la violencia contra las mujeres. ¡Dominemos la tecnología!" (APC, 2015)

\section{Referencias}

Asociación para el Progreso de las Comunicaciones (2015). Infografía: Mapeo de violencia contra las mujeres relacionada con la tecnología, iDominemos la tecnología! 8 datos importantes. Argentina. Recuperado de https://www.apc.org/es/ pubs/infograf\%C3\%ADa-mapeo-de-violencia-contra-las-mujeres-relacionada-con-la-tecnolog\%C3\%ADa-\%C2\%Aldominemos-la

Barrera L, Rodríguez C. (Coordinadoras) (2017). La violencia en línea contra las mujeres en México. México: Fundación para el Progreso de las Comunicaciones 
APC. Recuperado de https://www.apc.org/es/pubs/informe-la-violencia-en-l\%C3\%ADnea-contra-las-mujeres-en-m\%C3\%A9xico

Bonder, G. (2002) Las nuevas tecnologías de información y las mujeres: reflexiones necesarias. Santiago de Chile: CEPAL-ECLAC (Serie Mujer y Desarrollo). Recuperado de https://repositorio.cepal.org/bitstream/handle/11362/5894/S026404_ es.pdf;jsessionid=OF188EF7E88BAF574C227C47F544AB97?sequence=1

Bourdieu, P. (1998). La dominación masculina, Barcelona: Editorial Anagrama. Recuperado de https://www.ocac.cl/wp-content/uploads/2015/01/Pierre-Bourdeu-La-dominaci\%C3\%B3n-masculina.pdf

INEGI. Instituto Nacional de Estadística y Geografía (2015) Módulo sobre Ciberacoso 2015. MociBA. Documento Metodológico. México: INEGI. Recuperado de http:// www.beta.inegi.org.mx/contenidos/proyectos/investigacion/ciberacoso/2015/ doc/702825084745.pdf

Martínez M. M. C y Mújica M. A. (2010). México: violencia contra las mujeres y las tecnologias de información y comunicación México. Asociación para el Progreso de las Comunicaciones (APC). Recuperado de https://www.genderit.org/sites/default/ upload/mexico_ctryrpt_es_tics_violencia.pdf

Trecebits. Infografía: ¿Qué ocurre en un minuto en Internet en 2017? Recuperado de https://www.trecebits.com/2017/09/17/ocurre-minuto-internet-2017-infografia

Página web de Take Back The Tech. https://www.takebackthetech.net/mapit/

Página web de Colnodo. Uso estratégico de Internet para el desarrollo. Derechos de las mujeres en los espacios digitales. https://www.dominemoslatecnologia.org/

Página web de Facebook de la Dirección de Equidad de Género de la UABJo. https:// www.facebook.com/DIEG.UABJO.MX/

Página web de la Association for Progressive Communications. https://www.genderit.org/onlinevaw/ 